\title{
Land Use/Land Cover Dynamics in Upper Ribb Watershed, Lake Tana Sub Basin, Ethiopia
}

\author{
Asimamaw Nigusie Asitatikie* Teka Girmay Hishe \\ Department of Hydraulic and Water Resources Engineering, Debre Tabor University, Debre Tabor, Ethiopia
}

\begin{abstract}
Population growth causes land and water resources degradation in the Ethiopian highlands by changing the land use and land cover of the area. Land use/land cover change has been one of the factors responsible for altering the hydrologic response of watersheds. Various water resources projects planning and implementation will require knowledge of the extent of these changes on catchment hydrology. This study assesses the land use and land cover dynamics in Upper Ribb watershed. The land use land cover change analyses for three different years of 1973, 1995 and 2016 were performed using ERDAS Imagine 2014. An accuracy assessment was done for the 2016 land use and land cover classification and the Kappa coefficient, $\mathrm{K}=0.92$ which indicates the perfect classification. During this study most parts of the bush/shrub land were changed to grazing and cultivated land. The overall 43 years period $(1973$ - 2016) study shows that there was a dramatic increase of cultivated lands with $29.947 \%$. On the other hand bush/shrub lands were decreased by $34.195 \%$ for this study period.
\end{abstract}

Keywords: Upper Ribb watershed, ERDAS Imagine, Land use/cover, dynamics.

DOI: $10.7176 / \mathrm{JEES} / 10-2-01$

Publication date: February $29^{\text {th }} 2020$

\section{INTRODUCTION}

Land use/cover dynamics and subsequent conversion lead to loss of biodiversity, deterioration in the physical and chemical properties of soil which causes degradation of the land (Emadodin et al., 2009).

Land use/cover changes are highly pronounced in the developing countries that are characterized by agriculture based economies and rapidly increasing human populations. It is caused by a number of natural and human driving forces (Meyer and BL Turner, 1994). Natural effects such as climate change are only over a long period of time, whereas the effects of human activities are immediate and often direct. From the human factors population growth is the most important in Ethiopia (Tekle and Hedlund, 2000) as it is common in developing countries. Population growth has significant effect on land degradation, poverty and food insecurity in the northern Ethiopian highlands (Pender et al., 2001).

Some $85 \%$ of the population lives in rural areas and directly depend on the land for its livelihood. This means the demands of lands are increasing as population increases.

Population growth causes degradation of resources particularly forests that rely on the available land. Not only have this but poor land use practices and improper management systems played a significant role in causing high land degradation. So far limited measures have been taken to combat the problems.

The knowledge how land use/cover would be change as time goes will enable local governments and policy makers to formulate and implement effective and appropriate response strategies to minimize the undesirable effects of future land use/cover change or modifications.

This study aims application of ERDAS Imagine 2014 for classification of land use and cover change over the past 43 years in the Upper Ribb watershed. The main objective of this study was to analyze the land use and land cover dynamics between 1973 and 2016 in Upper Ribb Watershed

\section{Description of study area}

The Upper Ribb watershed is located in South Gonder Zone of the Amhara National Regional State of Ethiopia. It is located with a geographical coordinates of $12^{\circ} 35^{\prime}$ to $13^{\circ} 54^{\prime}$ north and $34^{\circ} 59^{\prime}$ to $41^{\circ} 25^{\prime}$ 'east latitude and longitude respectively. The Upper Ribb watershed originates from high (Guna) mountain at an elevation of 4090 m.a.s.l and drains to the northeast part of Lake Tana. It covers an area of $678.15 \mathrm{~km}^{2}$. 


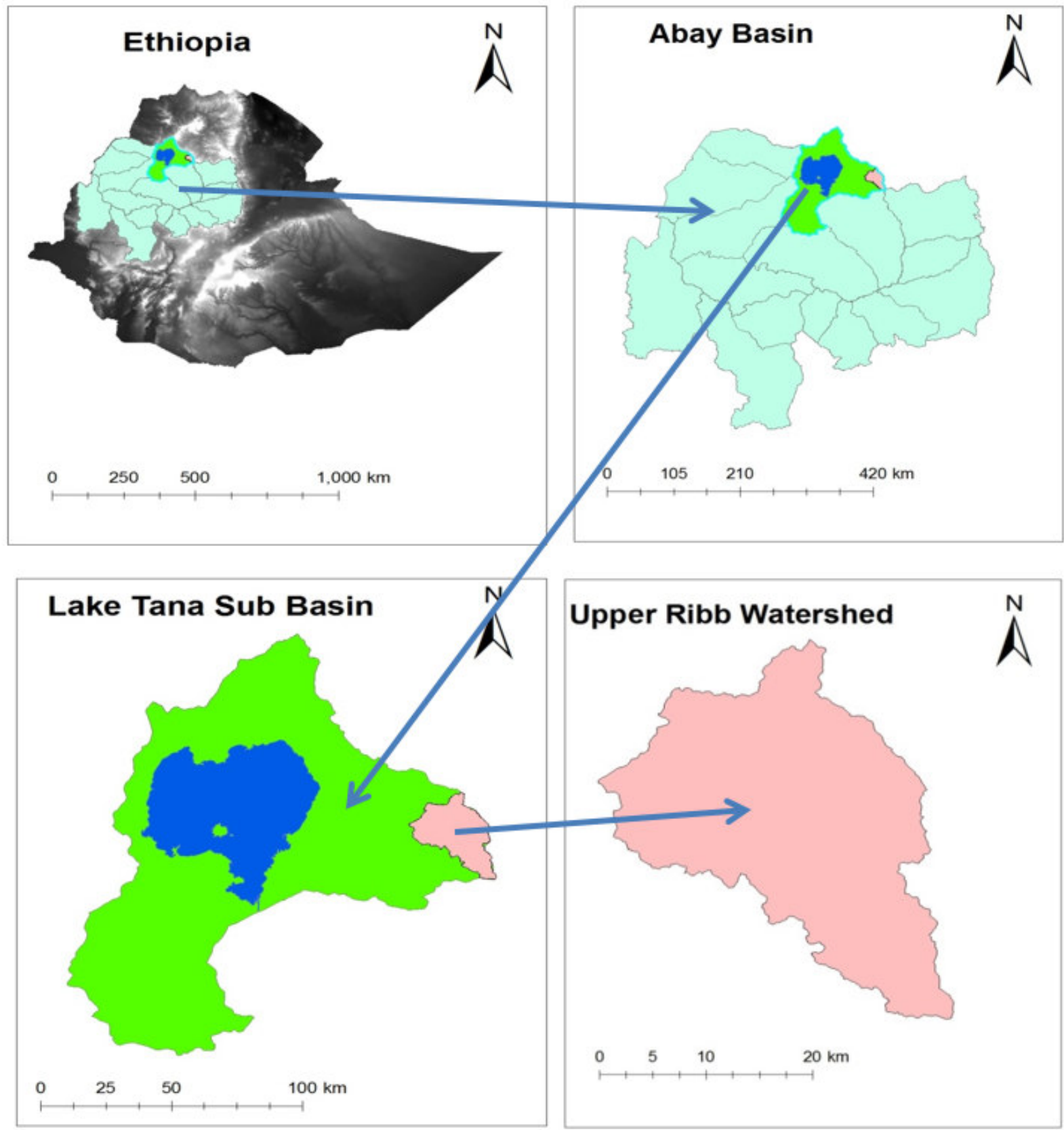

Figure 2. 1 Location of Upper Ribb Watershed

\section{Methods}

The general methodology followed for this study consist the following major activities.

Ground truth data (ground control points) were collected by asking the local elder man for the $1973 \& 1995$ years and an identification of the different types of land cover of the study area for the recent year 2016 using GPS.

After collection of necessary data, image classification and change detection analysis was done to identify land cover changes by processing the selected year image data.

Basically, the general methodology for the study can be described by the following flow Chart. 


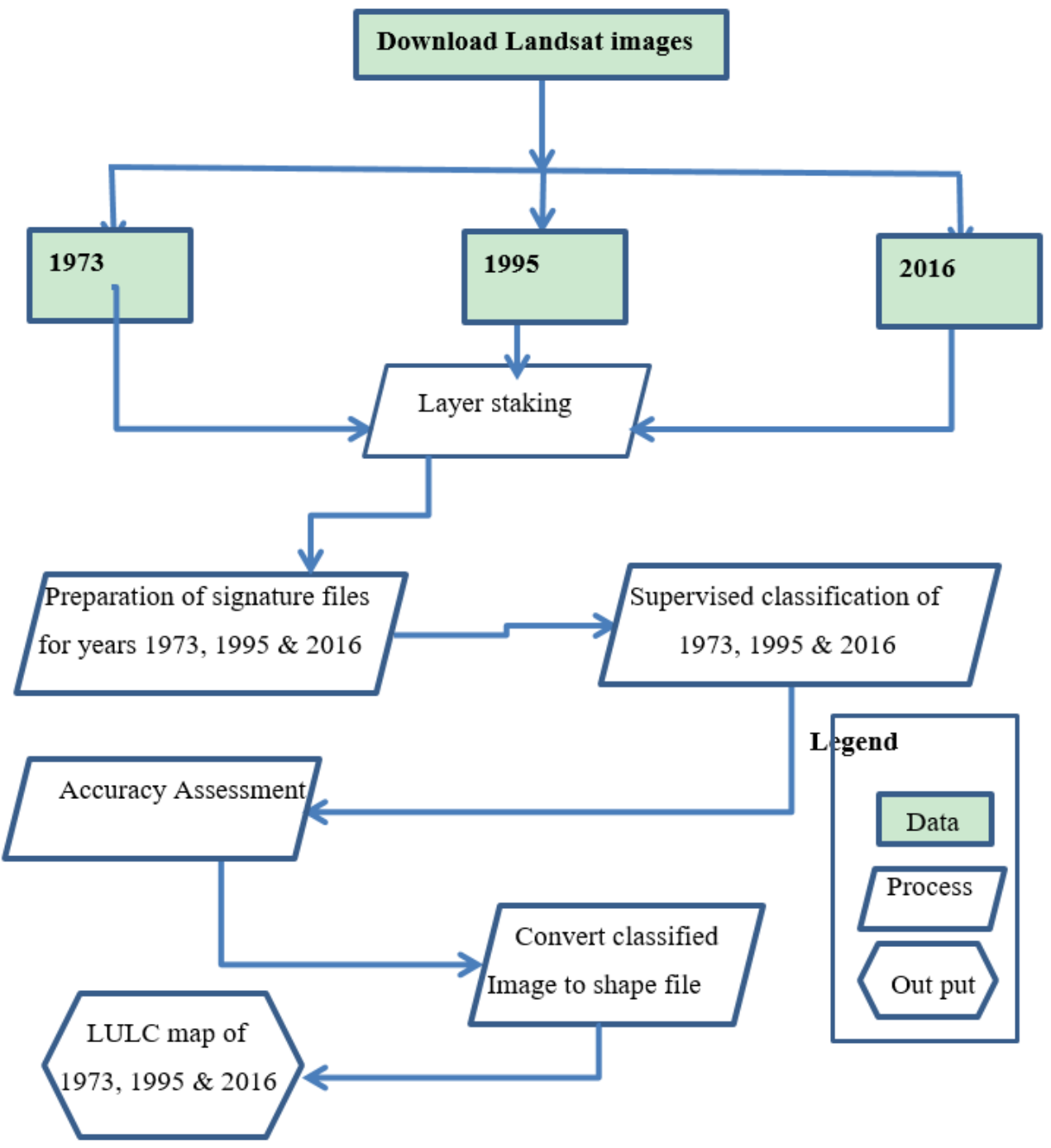

Figure 3.1 Framework of the Methodology Used

\subsection{Land use land cover data collection and analysis}

Land use and land cover (LULC) data in Upper Ribb Watershed was acquired from USGS earth explorer. The major data source for land cover/use image is http://earthexplorer.usgs.gov/ where free Landsat image is available. Four multi-temporal remotely sensed images were acquired for change detection for this study, including Landsat MSS/RBV 1973, Landsat TM 1995 and Landsat OLI/TIRS 2016. These images were downloaded in zipped files and extracted to Tiff format files. The satellite images used for this study were taken in the dry season. Dry season were selected since the satellite images were in good quality (free of cloud cover), easy for identification of cultivated lands and grazing lands. The process of detecting LULC from the satellite images was through image processing and classification of images.

LULC classes were determined based on the information acquired from previous knowledge, field observation of the sample areas and ground control points.

\subsubsection{Image Processing}

Landsat images were acquired in gray scale and a different image was downloaded for each one of the bands. By creating a composite image, the images could be displayed in color, most specifically in RGB style (Red, Green, and Blue). Displaying bands in the RGB format allows seeing different features within a scene and becoming more familiar with the scene to identify informational classes like urban areas, forests, agriculture, and water bodies. But this color may not look more natural. To display the composite image as in natural colors (a true color image) it must be combined. This was done through ERDAS Imagine by making layer stacking of images.

A layer stack is often used to combine separate image bands into a single multispectral image file. In order to analyze remotely sensed images, the different images representing different bands must be stacked. This allows different combinations of RGB to be shown in the view. After stacking the Landsat image sub-setting of Upper 
Ribb watershed satellite image was performed using the layer stacked images by the delineated watershed shape file.

Sub-setting is the process of clipping or cutting out a portion of an image for the area or image of interest.

Table 3. 1 Description of Landsat Images

\begin{tabular}{|l|l|l|l|}
\hline $\begin{array}{l}\text { Acquisition } \\
\text { date }\end{array}$ & Sensor & $\begin{array}{l}\text { Resolution } \\
(\mathrm{m})\end{array}$ & Producer \\
\hline March 26,1973 & MSS & 30 & United State Geological Survey (USGS) \\
\hline March 21, 1995 & TM & 30 & United State Geological Survey (USGS) \\
\hline April 16,2016 & OLI & 30 & United State Geological Survey (USGS) \\
\hline
\end{tabular}

\subsubsection{Land Use and Land Cover Classes}

Before the analysis is started, land use and land cover change studies usually need the development and the definition of homogeneous land use and land cover units. These have to be differentiated using the available data source such as remote sensing, any other relevant information and the previous local knowledge.

Hence, based on the priori knowledge of the study area and additional information from previous research in the study area (Garede and Minale, 2014) and (Ephrem , 2011), seven different types of land use and land cover has been identified for the Upper Ribb watershed. The descriptions of these land use and land covers are given in Table 3.2

Table 3.2 Land use and land cover classes

\begin{tabular}{|l|l|}
\hline LULC class & Description \\
\hline Cultivated land & $\begin{array}{l}\text { Areas used for crop cultivation, both annually and perennially. It is the area with standing } \\
\text { crop, tree crops, and crop lands where the crops were harvested. }\end{array}$ \\
\hline $\begin{array}{l}\text { Bush and Shrub } \\
\text { land }\end{array}$ & $\begin{array}{l}\text { Areas with bushes, shrubs and small trees, with little wood and mixed with some grasses. } \\
\text { It includes plantation trees and scrub vegetation at the fringes of forest cover and areas } \\
\text { dominated by scattered trees. }\end{array}$ \\
\hline Grazing land & $\begin{array}{l}\text { Areas covered with grass used for grazing, as well as bare lands that have little grass or } \\
\text { no grass cover. It also includes other small sized plant species. }\end{array}$ \\
\hline Water bodies & $\begin{array}{l}\text { Areas with surface water in the form of ponds, reservoirs, lakes, streams, rivers and its } \\
\text { main tributaries. }\end{array}$ \\
\hline Forest land & Land covered with dense trees which are mainly ever green forest land \\
Settlement Area & $\begin{array}{l}\text { Areas with low density to high density residential. It comprises both dispersed rural and } \\
\text { urban settlement areas. }\end{array}$ \\
\hline $\begin{array}{l}\text { Woody Savanna } \\
\text { Land }\end{array}$ & $\begin{array}{l}\text { Areas cover with wood mixed with higher grass cover including seasonal as well as } \\
\text { permanent wetlands. }\end{array}$ \\
\hline
\end{tabular}

\subsubsection{Image Classification}

Image classification is the process of assigning of pixels of continuous raster image to the different land cover classes. There are two ways to classify pixels into different categories namely supervised and unsupervised classification using ERDAS Imagine software. In unsupervised classification, the computer produces spectral classes based on the digital numbers (DN) without any direction from the user. It is used to cluster pixels in a data set into classes based on statistics only. These classes are spectral classes and their identity is not initially known, until they are compared with some reference data.

In supervised classification compared with computer-controlled unsupervised classification, the users have much closer control over the classification process. In this process, they select pixels that represent patterns they recognize or can identify with help from other sources. Knowledge of the data, the classes desired, and the algorithm to be used is required before they begin selecting training samples.

In this study, the land cover map was prepared based on the pixel based supervised classification through the procedure of: First, selecting of the training sites which are typically representative for the land cover classes. Thus, between 25 and 35 ground control points were collected for each land cover classes(cultivated, grazing, forest, bush/shrub, urban, savanna and water bodies) for the year 1973 \& 1995 by asking local elder people of the area, and for the year 2016 from ground truth. Then the signature files/training samples were created from those collected ground control points. Second, from the supervised classification methods the Maximum Likelihood supervised classification algorithm was used. This is due to the fact that unlike other classifiers it considers the spectral variation with in each category and the overlap that may occur among different classes (Campbell and Mortenson, 1989). The best grouping of unknown pixels was provided by the use of parameters of the maximum likelihood statistical method. In this particular study Maximum Likelihood classifier has been used in the supervised classification method.

\subsubsection{Accuracy Assessment of Image Classification}

After image classification accuracy assessment must be done to determine how well the classification process accomplished the task. This process involves generating a set of points in the classified imagery and comparing 
them with actual points on the ground through field work. The most widely used classification accuracy is in the form of error matrix which can be used to derive a series of descriptive and analytical statistics (Manandhar et al., 2009). The columns of the matrix depict the number of pixels per class for the reference data, and the rows show the number of pixels per class for the classified image. From this error matrix, a number of accuracy measures such as overall accuracy, user's accuracy, producer's accuracy and Kappa statistics are determined. The overall accuracy is used to indicate the accuracy of the whole classification (i.e. number of correctly classified pixels divided by the total number of pixels in the error matrix), whereas the other two measures indicate the accuracy of individual classes. User's accuracy is regarded as the probability that a pixel classified on the map actually represents that class on the ground or reference data, whereas product's accuracy represents the probability that a pixel on reference data has been correctly classified. Kappa statics is a type of technique used in accuracy assessment. It expresses the agreement between two categorical data sets.

In this study, accuracy assessment was performed using the available and the Google Earth Image together with previous knowledge of the area which used as reference data to generate testing data set by generating certain random testing points. A total of 200 testing sample points were selected randomly for the recent year 2016 and accuracy assessment was done.

\section{Results and Discussion}

\subsection{Land Use and Land Cover Change Analysis}

After the image processing and land cover detection, seven (Cultivated Land, Grazing Land, Bush and Shrub Land, Forest Cover, Water Body, Urban and Settlement Area \& Woody Savanna Land) land use and land cover classes were found for the year 1973, $1995 \& 2016$.

Images of March \& April (1973, 1975 \& 2016) were acquired, when crop harvesting had already been done and farmlands appear bare.

Analysis of the 1973 land sat satellite image revealed that bush/ shrub land constituted the largest proportion of land in Ribb Watershed with a value of $65.501 \%$, followed by cultivated, grazing and forest lands with $22.993 \%$, $6.851 \%$ and $4.259 \%$ coverage's respectively (Figure 4.1 and Table 4.1). Urban and water covers small percentages, i.e. $0.316 \%$ and $0.080 \%$ respectively.

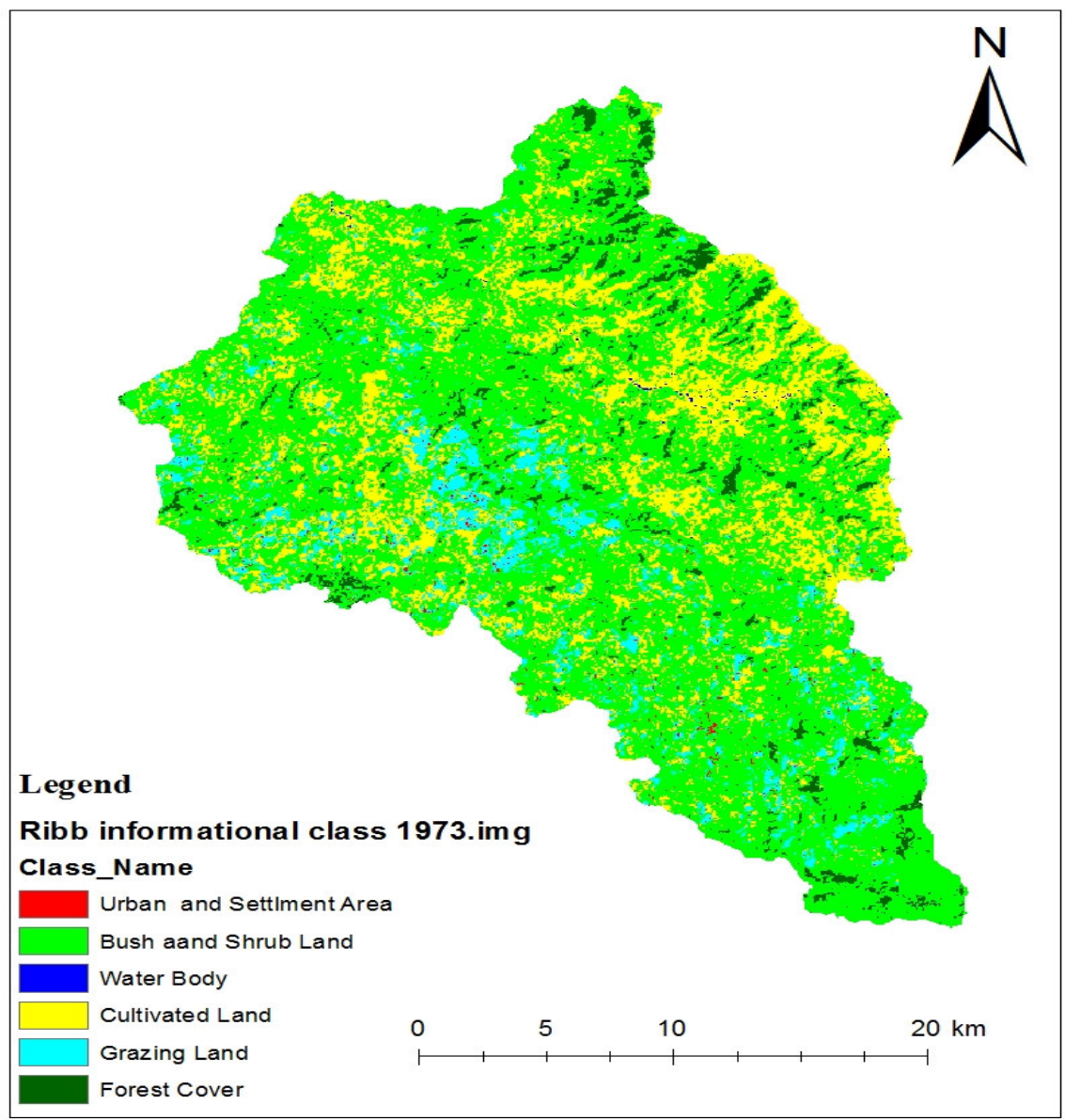

Figure 4. 1 Land use and land cover map of Upper Ribb Watershed in 1973 
According to maximum likelihood classification of 1995 land sat satellite image in Upper Ribb Watershed (Figure 4.2 and Table 4.1), the proportion of land allocated for cultivation expanded to $55.405 \%$. Furthermore, grazing land, urban area and water body have increased to $28.405 \%, 0.537 \%$ and $0.36 \%$ respectively. However, the proportions of bush/shrub land and forest cover have decreased to $13.516 \%$ and $1.775 \%$ respectively.

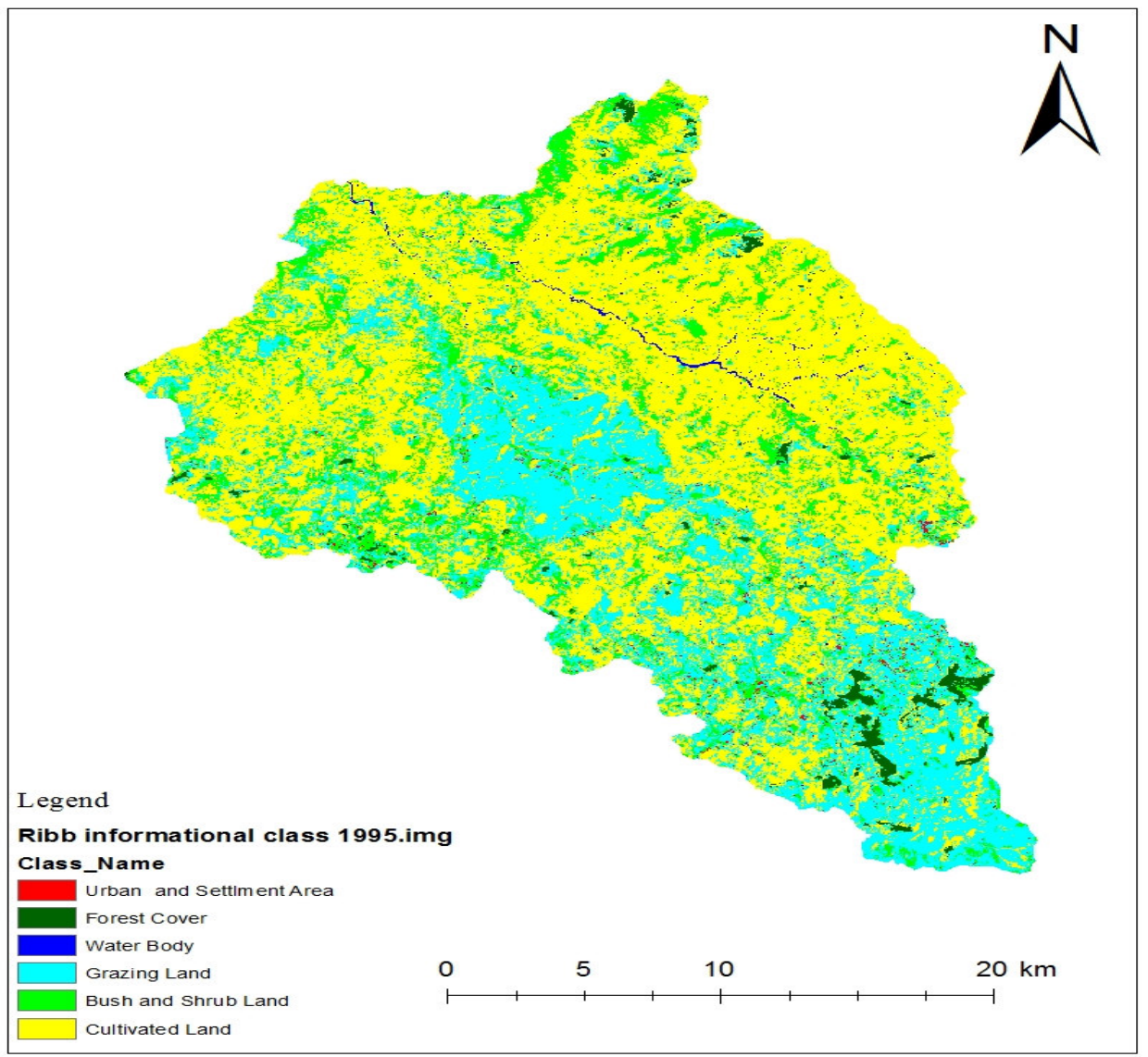

Figure 4. 2 Land use and land cover map of Upper Ribb Watershed in 1995

The maximum likelihood classification of 2016 land sat satellite image showed that the land cover classes (Figure 4.3 and Table 4.1) were also dominated by cultivated lands with $52.940 \%$, though the value decreases as it compared from the year 1995. It is also followed by the ever increasing bush/shrub land with $31.306 \%$ and the ever decreasing grazing land with $10.297 \%$. This indicates that recent conservation activities were taken in the area for watershed management. But this conservation practice cannot preserve the forest cover, which is decreased to $1.570 \%$

Other land cover classes also cover the remaining $3.887 \%$, with woody savanna grassland $2.069 \%$, urban and settlement area $1.406 \%$ and water body $0.412 \%$. 


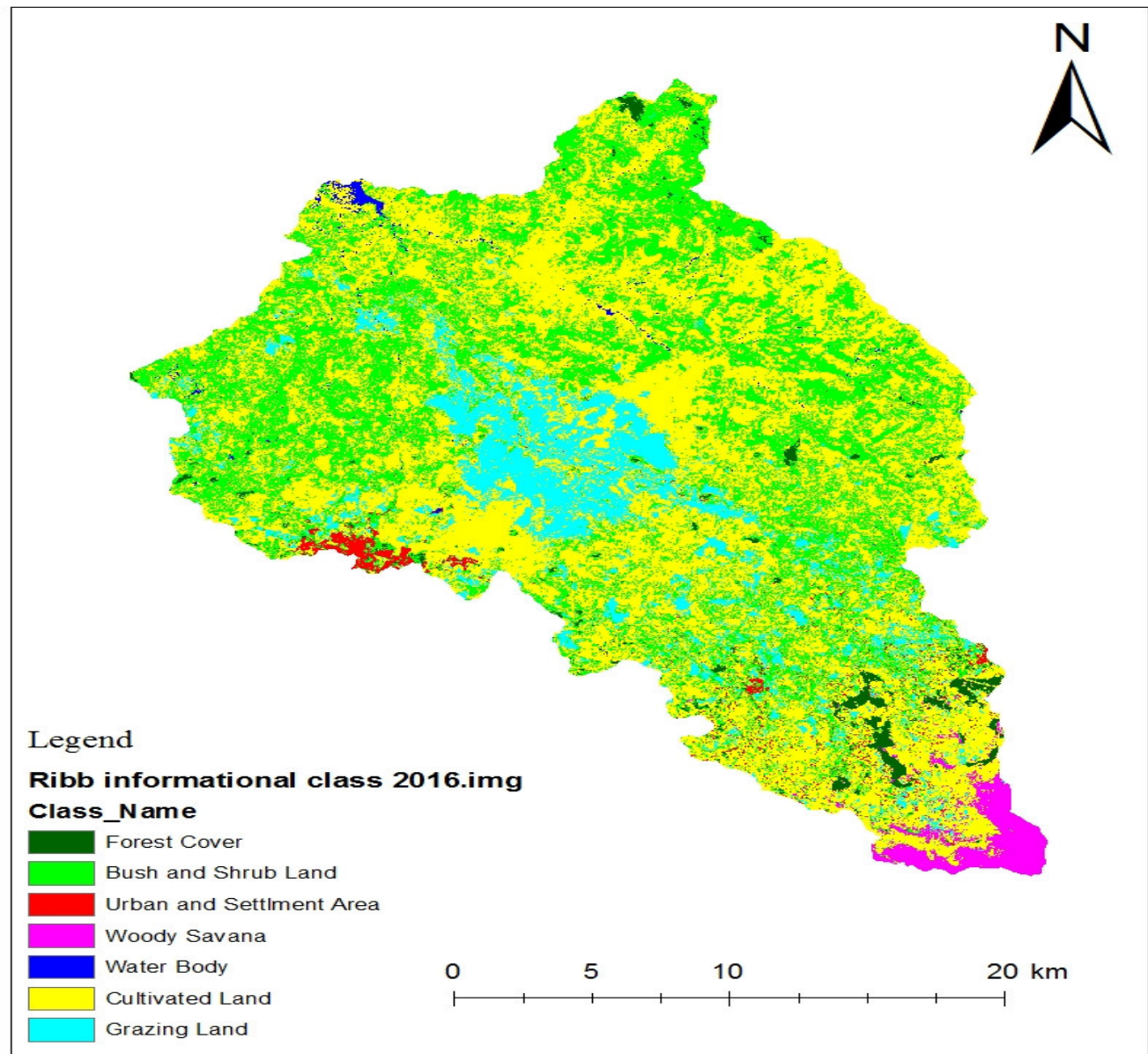

Figure 4. 3 Land Use and land cover map of Upper Ribb Watershed in 2016

Table 4. 1 Summary of land use/cover change percentage of Upper Ribb Watershed

\begin{tabular}{|l|l|l|l|l|l|l|}
\hline \multirow{2}{*}{$\begin{array}{l}\text { Land cover } \\
\text { classes }\end{array}$} & \multicolumn{1}{l}{ Years } & \multicolumn{1}{l|}{ Land use change detection } \\
\cline { 2 - 8 } & 1973 & 1995 & 2016 & $1973-1995$ & $1995-2016$ & $1973-2016$ \\
\hline Cultivated Land & 22.993 & 55.405 & 52.940 & +32.412 & -2.464 & +29.947 \\
\hline Grazing Land & 6.851 & 28.405 & 10.297 & +21.554 & -18.107 & +3.446 \\
\hline Bush and Shrub Land & 65.501 & 13.516 & 31.306 & -51.985 & +17.790 & -34.195 \\
\hline Forest Cover & 4.259 & 1.775 & 1.570 & -2.485 & -0.205 & -2.690 \\
\hline Water Body & 0.080 & 0.363 & 0.412 & +0.283 & +0.049 & +0.331 \\
\hline Urban and Settlement Area & 0.316 & 0.537 & 1.406 & +0.221 & +0.869 & +1.090 \\
\hline Woody Savanna Land & & & 2.069 & & & +2.069 \\
\hline
\end{tabular}

From above result (Table 4.1) it can be observed that there was a dramatic increase of cultivated and grazing lands for the first period $(1973-1995)$ with +32.412 and +21.554 respectively. On the other hand bush/shrub lands were decreased by $51.985 \%$ for this period. However, the bush/shrub lands show appreciable increase during the second period $(1995-2016)$ with $+17.790 \%$. On the contrary, the grazing land showed a significant decrease in the second period $(1995-2016)$ with $18.107 \%$. And also forest cover decreases for the first and second period, but urban area, water body and woody savanna lands were increased both in the first and the second periods. This increment of water body was due to impoundment of the Ribb dam reservoir and also the storage of Selamko reservoir in the Upper Ribb watershed. The increment of bush/shrub land and woody savanna lands in the second period were due to conservation activities taken in the area for watershed management particularly the conservation activities taken in Guna mountain were responsible for the expansion of woody savanna lands in the southern edge of the Watershed. Such recent conservation works for expansion of bush/shrub lands in the area were from preserving some cultivated lands and protecting overgrazing areas. This causes the cultivated lands to decrease in the second period though it shows slightly.

Previous similar studies in this watershed and other parts of the country also reflect similar results. For instance, (Garede and Minale, 2014) showed the cultivated \& settlement land, shrub land and grassland coverage during 2011 were $70.43 \%, 14 \%$ and $7.58 \%$ respectively for the whole Ribb catchment in the north western part of Ethiopia. (Yeshaneh et al., 2013) stated that crop field coverage in Koga watershed in 2010 were $76.83 \%$. 
(Geremew, 2013) shows that the cultivated area was increased by $45 \%$, while forest, grassland, shrub land and water was decreased by $2 \%, 34 \%, 5.7 \%$ and $4.9 \%$ respectively from 1986 to 2001 .

(Hadgu, 2008) indicating a sharp reduction of natural habitats and an increase in agricultural land in the highlands of Tigray, northern Ethiopia over a period of 41 years $(1964-2005)$. He reported that shrub land was dominant in 1964 covering $46 \%$ of the area followed by woodland with coverage of $28 \%$ of the area. However, agricultural land was dominant in both 1994 and 2005 covering 34\% and 40\% respectively. The next dominant LULC types in 1994 and 2005 were shrub land with coverage of $21 \%$ and $39 \%$.

(Andualem and Gebremariam, 2015) reported that there was an increase of cultivated lands and a decrease of forest cover by 33.79 and 1.4 percent respectively in Gilgel Abbay watershed, north western Ethiopia from the periods $1986-2011$.

(Bewket, 2003) identifies agricultural conversion of $79 \%$ of the Riverine forests of the Chemoga watershed within the Blue Nile basin from 1957 to 1998. (Rientjes et al., 2011) also presented the agricultural land, shrub land and grassland coverage during 2001 were $62.7 \%, 8.9 \%$ and $8.8 \%$ respectively for Upper Gilgel Abay catchment.

\subsection{Accuracy Assessment}

Accuracy assessment involves generating a set of points in the classified imagery and comparing them with actual points on the ground through field work. The most widely used classification accuracy is in the form of error matrix which can be used to derive a series of descriptive and analytical statistics (Manandhar et al., 2009). The columns of the matrix depict the number of pixels per class for the reference data, and the rows show the number of pixels per class for the classified image. From this error matrix, a number of accuracy measures such as overall accuracy, user's and producer's accuracy determined. The overall accuracy is used to indicate the accuracy of the whole classification (i.e. number of correctly classified pixels divided by the total number of pixels in the error matrix), whereas the other two measures indicate the accuracy of individual classes. User's accuracy is regarded as the probability that a pixel classified on the map actually represents that class on the ground or reference data, whereas product's accuracy represents the probability that a pixel on reference data has been correctly classified. In this study an accuracy assessment was made by using a confusion matrix with 200 randomly selected points (Table 4.2) by using land use maps, ground truth points and Google Earth. Great importance was given to the representation of different LU/LC classes by these randomly chosen points.

Table 4. 2 Confusion matrixes for the classification of 2016 land use

\begin{tabular}{|c|c|c|c|c|c|c|c|c|c|}
\hline \multirow{2}{*}{$\begin{array}{l}\text { Classified } \\
\text { Image }\end{array}$} & \multicolumn{8}{|c|}{ Ground Truth } & \multirow{2}{*}{$\begin{array}{l}\text { User's } \\
\text { Accuracy }\end{array}$} \\
\hline & Cultivated & Bush & Grazing & Forest & Urban & Water & Woody & Total & \\
\hline Cultivated & 101 & 0 & 2 & 0 & 0 & 0 & 0 & 103 & $98.06 \%$ \\
\hline Bush & 2 & 31 & 2 & 1 & 0 & 0 & 0 & 36 & $86.11 \%$ \\
\hline Grazing & 1 & 1 & 46 & 0 & 0 & 0 & 0 & 48 & $95.83 \%$ \\
\hline Forest & 0 & 0 & 1 & 6 & 0 & 0 & 0 & 7 & $85.71 \%$ \\
\hline Urban & 0 & 0 & 0 & 0 & 1 & 0 & 0 & 1 & $100 \%$ \\
\hline Water & 0 & 0 & 0 & 0 & 0 & 1 & 0 & 1 & $100 \%$ \\
\hline Woody & 0 & 0 & 0 & 0 & 0 & 0 & 4 & 4 & $100 \%$ \\
\hline Total & 104 & 32 & 51 & 7 & 1 & 1 & 4 & 200 & \\
\hline $\begin{array}{l}\text { Producer' } \\
\text { s accuracy }\end{array}$ & $97.12 \%$ & $96.88 \%$ & $90.20 \%$ & $85.71 \%$ & $100 \%$ & $100 \%$ & $100 \%$ & $\begin{array}{l}\text { Overal } \\
=96 \%\end{array}$ & Accuracy \\
\hline
\end{tabular}

The 2016 land use and land cover classification has showed, user's accuracy and producer's accuracy are greater than $85 \%$, as well the overall accuracy of $96 \%$ (Table 4.2 ). These values indicate the land sat and the methodologies used were so accurate. The Kappa coefficient also calculated, with a value of $\mathrm{K}=0.92$ which indicated the classification is almost perfect since it is between 0.81 and 1.00 (Landis and Koch, 1977). Thus, based on this expression the land use and land cover classification for 2016 image in this study was almost perfect.

\section{Conclusions}

This study has addressed the land use and land cover dynamics in Upper Ribb watershed for over 43 years period using Landsat satellite images from USGS earth explorer. The classification of land use and land covers were performed on ERDAS Imagine 2014, which were integrated with other GIS data.

The study shows that Upper Ribb watershed has experienced a significant change in land use and land cover over the past 43 years. This can be recognized that bush/shrub lands were significantly changed to cultivated and grazing lands with a decrease of forests throughout the study periods. The results revealed that the magnitudes of the cultivated land were increased by $29.947 \%$ and the bush/shrub lands were decreased by $34.195 \%$ through the study period. Degradation of cultivable and potential areas is the major problem in Ethiopia particularly in the 
highlands for many years and will continue in the future except appropriate watershed management activities are taken. This is due to the topography of the watershed, high densely population and poor management practices taken in the watershed. To manage this problem, the local government and other stakeholders should implement appropriate watershed management activities. This will done by forest resources development, protection and use strategies need to be devised to encourage the increasing/expanding bushes/shrub land.

\section{REFERENCES}

ANDUALEM, T. G. \& GEBREMARIAM, B. 2015. Impact Of Land Use Land Cover Change On Stream Flow And Sediment Yield: A Case Study Of Gilgel Abay Watershed, Lake Tana Sub-Basin, Ethiopia. Arba Minch University.

BEWKET, W. 2003. Towards integrated watershed management in highland Ethiopia: the Chemoga watershed case study.

CAMPBELL, W. \& MORTENSON, D. 1989. Ensuring the quality of geographic information system data: a practical application of quality control.

GAREDE, N. \& MINALE, A. 2014. Land Use/Cover Dynamics in Ribb Watershed, North Western Ethiopia. J. Nat. Sci. Res, 4, 16.

GEREMEW, A. A. 2013. Assessing the impacts of land use and land cover change on hydrology of watershed: a case study on Gigel-Abbay Watershed, Lake Tana Basin, Ethiopia.

HADGU, K. M. 2008. Temporal and spatial changes in land use patterns and biodiversity in relation to farm productivity at multiple scales in Tigray, Ethiopia.

LANDIS, J. R. \& KOCH, G. G. 1977. The measurement of observer agreement for categorical data. biometrics, $159-174$

MANANDHAR, R., ODEH, I. O. \& ANCEV, T. 2009. Improving the accuracy of land use and land cover classification of Landsat data using post-classification enhancement. Remote Sensing, 1, 330-344.

RIENTJES, T., HAILE, A., KEBEDE, E., MANNAERTS, C., HABIB, E. \& STEENHUIS, T. 2011. Changes in land cover, rainfall and stream flow in Upper Gilgel Abbay catchment, Blue Nile basin-Ethiopia. Hydrology and Earth System Sciences, 15, 1979.

YESHANEH, E., WAGNER, W., EXNER-KITTRIDGE, M., LEGESSE, D. \& BLÖSCHL, G. 2013. Identifying land use/cover dynamics in the Koga catchment, Ethiopia, from multi-scale data, and implications for environmental change. ISPRS International Journal of Geo-Information, 2, 302-323. 